\title{
Renal expression of cytokines and chemokines in diabetic nephropathy
}

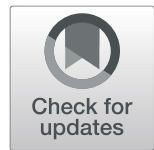

Liliane Silvano Araújo', Bianca Gonçalves Silva Torquato', Crislaine Aparecida da Silva', Maria Luíza Gonçalves dos Reis Monteiro', Ana Luisa Monteiro dos Santos Martins', Marcos Vinícius da Silva², Marlene Antônia dos Reis ${ }^{1}$ and Juliana Reis Machado ${ }^{1 *}$ (ID

\begin{abstract}
Background: Diabetic nephropathy (DN) is the leading cause of end-stage renal disease worldwide. Inflammatory mediators have been implicated in the pathogenesis of DN, thus considered an inflammatory disease. However, further studies are required to assess the renal damage caused by the action of these molecules. Therefore, the objective of this study was to analyze the expression of cytokines and chemokines in renal biopsies from patients with DN and to correlate it with interstitial inflammation and decreased renal function.

Methods: Forty-four native renal biopsies from patients with DN and 23 control cases were selected. In situ expression of eotaxin, MIP-1a (macrophage inflammatory protein-1a), IL-8 (interleukin-8), IL-4, IL-10, TNF-a (tumor necrosis factor- $\alpha$ ), TNFR1 (tumor necrosis factor receptor-1), IL-1 $\beta$, and IL- 6 were evaluated by immunohistochemistry.

Results: The DN group showed a significant increase in IL-6 ( $p<0.0001), \mathrm{IL}-1 \beta(p<0.0001), \mathrm{IL}-4(p<0.0001)$ and eotaxin $(p=0.0012)$ expression, and a decrease in TNFR1 $(p=0.0107)$ and IL-8 $(p=0.0262)$ expression compared to the control group. However, there were no significant differences in IL-10 $(p=0.4951)$, TNF- $a(p=0.7534)$, and MIP1a $(p=0.3816)$ expression among groups. Regarding interstitial inflammation, there was a significant increase in IL- 6 in scores 0 and 1 compared to score $2(p=0.0035)$, in IL-10 in score 2 compared to score $0(p=0.0479)$, and in eotaxin in score 2 compared to scores 0 and $1(p<0.0001)$, whereas IL-8 $(p=0.0513)$ and MIP-1a $(p=0.1801)$ showed no significant differences. There was a tendency for negative correlation between eotaxin and estimated glomerular filtration rate (eGFR) $(p=0.0566)$.

Conclusions: Our results indicated an increased in situ production of cytokines and chemokines in DN, including IL-6, IL-1 $\beta, I L-4$, and eotaxin. It was observed that, possibly, eotaxin may have an important role in the progression of interstitial inflammation in DN and in eGFR decrease of these patients.
\end{abstract}

Keywords: Diabetic nephropathy, Cytokines, Chemokines, Renal biopsy, Interstitial inflammation

\footnotetext{
* Correspondence: juliana.patologiageral@gmail.com

'Discipline of General Pathology, Institute of Biological and Natural Sciences of Federal University of Triângulo Mineiro, Praça Manoel Terra, 330, Nossa Senhora da Abadia, Uberaba, Minas Gerais 38025-015, Brazil

Full list of author information is available at the end of the article
}

(c) The Author(s). 2020 Open Access This article is licensed under a Creative Commons Attribution 4.0 International License, which permits use, sharing, adaptation, distribution and reproduction in any medium or format, as long as you give appropriate credit to the original author(s) and the source, provide a link to the Creative Commons licence, and indicate if changes were made. The images or other third party material in this article are included in the article's Creative Commons licence, unless indicated otherwise in a credit line to the material. If material is not included in the article's Creative Commons licence and your intended use is not permitted by statutory regulation or exceeds the permitted use, you will need to obtain permission directly from the copyright holder. To view a copy of this licence, visit http://creativecommons.org/licenses/by/4.0/ The Creative Commons Public Domain Dedication waiver (http://creativecommons.org/publicdomain/zero/1.0/) applies to the data made available in this article, unless otherwise stated in a credit line to the data. 


\section{Background}

Diabetic nephropathy (DN) is a chronic microvascular complication that affects about 20 to $30 \%$ of patients with type 2 diabetes mellitus (T2DM). It is considered the leading cause of end-stage renal failure requiring renal replacement therapy $[1,2]$, although its pathogenesis has not yet been fully elucidated. Immune and inflammatory mechanisms play important role in the development and progression of DN, which is considered a chronic inflammatory disease [3, 4]. Several cells, such as monocytes, macrophages, and lymphocytes, as well as chemokines and cytokines, have been implicated in this process $[5,6]$. Among them, it is known that IL$1 \beta$, IL-6, TNF- $\alpha$ (tumor necrosis factor- $\alpha$ ), IL-8, MIP- $1 \alpha$ (macrophage inflammatory protein-1 $\alpha$ ) are relevant for the development of $\mathrm{DN}$, as they are potentially involved in the onset of disease complications [7-9].

Patients with DN have a predominance of increased plasmatic and urinary levels of inflammatory mediators, both in early and end stages of the disease [9-13]. However, the extent of renal damage caused by immune cellderived cytokines and chemokines and the importance of such inflammatory mechanisms on the development and progression of DN requires further investigation $[14,15]$.

Renal biopsies are considered the gold standard for diagnosis of glomerulopathies; however, diabetic patients are only subjected to renal biopsies in cases of atypical clinical courses of DN. Atypical presentations include microalbuminuria without diabetic retinopathy, a rapid decline in eGFR, rapidly increasing proteinuria, a sudden onset of nephrotic syndrome, hematuria, a period of less than 5 years from the diagnosis of diabetes to the onset of nephropathy or signs and symptoms of systemic diseases [16, 17].

However, further studies using this type of samples to investigate mechanisms associated with the expression of inflammatory mediators involved in DN pathogenesis are required, as level of these mediators reflects the direct action of molecules in organs, as well as the relationship with DN. Therefore, this study aims to analyze the expression of cytokines and chemokines such as IL-1 $\beta$, IL-6, IL-4, IL-10, TNF- $\alpha$, TNFR1 (tumor necrosis fator receptor-1), IL-8, MIP-1 $\alpha$ e eotaxin in renal biopsies from patients with $\mathrm{DN}$ and determine its correlation with interstitial inflammation and decreased renal function.

\section{Methods}

\section{Patients}

Forty-four cases of native renal biopsies from adult patients diagnosed with DN were selected from the Renal Pathology Service database of the Federal University of Triângulo Mineiro (UFTM), Uberaba-MG, Brazil, from 1996 to 2018. All cases of DN in patients over 18 years old, with satisfactory samples for analysis and without overlap with other renal diseases were included in the study. Control group $(n=23)$ consisted of kidneys obtained from autopsies of patients older than 18 years, with no evidence of infection or previous renal changes. Cases with autolysis, acute tubular necrosis, and congestion with moderate to severe changes were excluded from control group. These samples were obtained from the Pathology Service of the University of São Paulo/ Ribeirão Preto. This study was approved by the Ethics and Research Committee of the Federal University of Triângulo Mineiro (no. 3.001.006).

\section{Renal histopathology}

The diagnosis of DN was performed with three samples used for light microscopy (LM), direct immunofluorescence (IF) and transmission electron microscopy (TEM) according to the standard procedures [18].

For LM, 2- $\mu \mathrm{m}$ paraffin sections were stained with hematoxylin and eosin $(\mathrm{H} \& \mathrm{E})$, Sirius red, methenamine silver, and Masson's trichrome. LM was used to analyze morphological changes and interstitial inflammation. Interstitial inflammation in DN was scored as score 0 (absence of interstitial inflammation), score 1 (presence of inflammatory infiltrate exclusively around the atrophic tubules) and score 2 (inflammatory infiltrate also occurs in areas other than around atrophic tubules). DN classes were defined according to the pathologic classification of DN [19].

For IF, IgG, IgM, IgA, kappa and lambda light chains, C3 and $\mathrm{C} 1 \mathrm{q}$ complement fractions and fibrinogen were detected in $2-\mu \mathrm{m}$ frozen sections using fluorescein isothiocyanate (FITC)-conjugated antibodies (Dako, Copenhagen, Denmark). IF was used to exclude or identify renal diseases overlapping DN. For TEM, tissue was fixed in 2.5\% Karnovsky $+0.2 \%$ ruthenium red, then fixed in $2 \%$ osmium tetroxide. Next, was dehydrated using a graded series of alcohol and acetone solutions before embedding in Epon 812 resin. Ultra-thin sections of $60 \mathrm{~nm}$ were prepared and placed in nickel grids. Sections were then stained with uranyl acetate and examined under a transmission electron microscope (EM-900; Zeiss, Germany) [18]. TEM was used to measure thickness of the glomerular basement membrane (GBM) and to exclude or identify renal diseases overlapping DN. All cases of DN overlapping with other renal diseases were excluded from the study.

\section{Immunohistochemistry}

Immunohistochemistry was performed manually on slides containing $2-\mu \mathrm{m}$ paraffin-embedded tissue sections using the Novolink non-biotin polymer system (Novolink Polymer Detection System Kit; BL, UK) according to the manufacturer's recommendations. Specifications of the antibodies used are summarized in Table 1. 
Table 1 Immunohistochemistry specifications

\begin{tabular}{|c|c|c|c|c|}
\hline Primary antibody & Supplier & Clone or code & Antigenic recovery & Concentration \\
\hline Anti-eotaxin monoclonal antibody & Thermo Fisher Scientific & 43,911 & Citrate $\mathrm{pH} 6.0$ & $1: 100$ \\
\hline $\begin{array}{l}\text { Anti-MIP-1a (macrophage inflammatory protein-1a) } \\
\text { (CCL3) polyclonal antibody }\end{array}$ & Thermo Fisher Scientific & PA5-32496 & Citrate $\mathrm{pH} 6.0$ & $1: 1600$ \\
\hline Anti-IL-4 (interleukin-4) polyclonal antibody & Thermo Fisher Scientific & PA5-25165 & Citrate $\mathrm{pH} 6.0$ & $1: 1300$ \\
\hline Anti-IL-8 (CXCL8) polyclonal antibody & Thermo Fisher Scientific & PA5-79113 & Citrate $\mathrm{pH} 6.0$ & $1: 1400$ \\
\hline Anti-IL-10 polyclonal antibody & Thermo Fisher Scientific & PA5-79457 & Citrate $\mathrm{pH} 6.0$ & $1: 1200$ \\
\hline Anti-TNF-a (tumor necrosis factor-a) monoclonal antibody & Thermo Fisher Scientific & $2 \mathrm{C} 8$ & Citrate $\mathrm{pH} 6.0$ & 1:1200 \\
\hline $\begin{array}{l}\text { Anti-TNF Receptor I (tumor necrosis fator receptor-1) } \\
\text { monoclonal antibody }\end{array}$ & abcam & H398 & Citrate $\mathrm{pH} 6.0$ & $1: 300$ \\
\hline Anti-IL-1 $\beta$ polyclonal antibody & Novus Biologicals & NBP1-19775 & Citrate $\mathrm{pH} 6.0$ & $1: 40$ \\
\hline Anti-IL-6 polyclonal antibody & abcam & $a b 6672$ & Citrate $\mathrm{pH} 6.0$ & $1: 300$ \\
\hline
\end{tabular}

\section{Quantification of in situ immunostaining}

All fields of renal biopsy samples and 40 fields of autopsy kidney fragments, which included glomerular and tubulointerstitial compartments, were analyzed. Immunostained cells showing an intense brownish staining were marked by the observer using the interactive AxionCam ICc 5 (Zeiss, Germany) image analysis system with a $40 \times$ objective (final magnification of $1600 \times$ ). Results were expressed as percentage of marked area compared to total area of the analyzed fields.

\section{Statistical analysis}

A spreadsheet (Microsoft Excel) was created for statistical analysis. Data analysis was performed using GraphPad Prism version 7.0 (GraphPad Software, USA). Normality was tested using Kolmogorov-Smirnov test. In cases of normal distribution and similar variances, parametric ANOVA (F) test was used, followed by posthoc Tukey's test and Student's $t$-test (t). In cases of a non-normal distribution, Kruskal-Wallis $(\mathrm{H})$ test was used, followed by post-hoc Dunn's test and MannWhitney (U) test. Proportions were compared by Chisquare test $\left(\chi^{2}\right)$. Pearson's test $(r)$ was used to determine correlations with parametric variables and Spearman's test $(\mathrm{rS})$ for non-parametric variables. Differences were considered statistically significant when $p<0.05$.

\section{Results}

\section{General characteristics of control and DN groups}

A total of 44 cases of DN were selected. Subjects had a median age of $53(23-75)$ years, most were male (24; $54.55 \%)$ and white $(34 ; 77.27 \%)$. Subjects in control group $(n=23)$ had a median age of $44(19-80)$ years with male predominance $(12 ; 52.17 \%)$.

Most DN patients were hypertensive (26; 59.1\%), had a mean time since diagnosis of diabetes mellitus of $13.66 \pm 6.58$ years, and a mean GBM thickness of $750.69 \pm 184.03 \mathrm{~nm}$. Laboratorial data of these patients showed mean creatinine levels of $2.22 \pm 1.47 \mathrm{mg} / \mathrm{dL}$ and mean urea levels of $81.9 \pm 41.9 \mathrm{mg} / \mathrm{dL}$. The eGFR was $48.46 \pm 34.51 \mathrm{~mL} / \mathrm{min} / 1.73 \mathrm{~m}^{2}$. The mean proteinuria was within the nephrotic range with values of $5.02 \pm$ 4.35 g/day. Regarding DN classification, 27 (61.5\%) biopsies were classified as class III, corresponding to the nodular sclerosis class (Kimmelstiel-Wilson nodules), 11 (25\%) as class IV, and 6 as classes I, IIa, and IIb, with 2 $(4.5 \%)$ cases in each class. General characteristics of the patients are summarized in Table 2.

Considering the fact that the majority (87\%) of cases had advanced disease, we performed analyzes comparing patients with eGFR $<60 \mathrm{~mL} / \mathrm{min} / 1.73 \mathrm{~m}^{2} \mathrm{X}$ patients with eGFR $>60 \mathrm{~mL} / \mathrm{min} / 1.73 \mathrm{~m}^{2}$ in $\mathrm{DN}$ group, as follow: IL-6 ( $p=0.8129 ; \mathrm{U}=85) ; \mathrm{IL}-1 \beta \quad(p=0.2197 ; \mathrm{t}=$ 1.252); IL-4 $(p=0.8329 ; \mathrm{t}=0.2128)$; TNFR1 $(p=0.0996$; $\mathrm{t}=1.698) ; \mathrm{IL}-10 \quad(p=0.6553 ; \mathrm{t}=0.4507) ; \mathrm{TNF}-\alpha \quad(p=$ $0.2874 ; \mathrm{t}=1.082) ;$ eotaxin $(p=0.0819 ; \mathrm{t}=1.795) ; \mathrm{IL}-8$ $(p=0.8882 ; \mathrm{t}=0.1417)$ and MIP- $1 \alpha \quad(p=0.1166 ; \mathrm{t}=$ 1.614). Thus, we believe the results of this study express the disease mechanism and are not directly related to end-stage renal disease.

\section{Role of cytokines and chemokines in diabetic nephropathy}

Expression profile of inflammatory cytokines and chemokines was analyzed in patients with $\mathrm{DN}$ and this group showed a significant increase in IL-6 $(p<0.0001$; $\mathrm{U}=82$, Fig. $1 \mathrm{a}$ and $\mathrm{b}), \mathrm{IL}-1 \beta(p<0.0001 ; \mathrm{t}=5.16$, Fig. $1 \mathrm{c}$ and $\mathrm{d})$, and IL-4 $(p<0.0001 ; \mathrm{U}=182$, Fig. $1 \mathrm{e}$ and $\mathrm{f})$ and a decrease in TNFR1 $(p=0.0107 ; \mathrm{t}=2.631$, Fig. $2 \mathrm{a}$ and b) compared to the control group. In contrast, there were no significant differences between groups for the cytokines IL-10 ( $p=0.4951 ; \mathrm{t}=0.6862$, Fig. $2 \mathrm{c}$ and $\mathrm{d})$ and TNF- $\alpha$ ( $p=0.7534 ; \mathrm{t}=0.3155$, Fig. $2 \mathrm{e}$ and $\mathrm{f})$.

Analysis of chemokine expression showed a significant increase in eotaxin ( $p=0.0012 ; \mathrm{U}=265.5$, Fig. 3a and b) expression and a decrease in IL-8 $(p=0.0262 ; \mathrm{t}=2.275$, Fig. 3c and d) expression in DN group compared to control group. However, there were no significant 
Table 2 General characteristics of Control and DN groups

\begin{tabular}{|c|c|c|}
\hline & $\begin{array}{l}\text { Control Group } \\
(\boldsymbol{n}=23)\end{array}$ & $\begin{array}{l}\text { DN Group } \\
(\boldsymbol{n}=44)\end{array}$ \\
\hline \multicolumn{3}{|l|}{ Age (years) } \\
\hline Median (Min-Max) & $44(19-80)$ & $53(23-75)$ \\
\hline Mean $\pm S D$ & $47 \pm 16.57$ & $50.3 \pm 13.73^{a}$ \\
\hline \multicolumn{3}{|l|}{ Gender $\mathrm{n}(\%)$} \\
\hline Male & $12(52.17 \%)$ & $24(54.55 \%)^{b}$ \\
\hline Female & $11(47.83 \%)$ & $20(45.55 \%)$ \\
\hline \multicolumn{3}{|l|}{ Color n (\%) } \\
\hline White & & $34(77.27 \%)$ \\
\hline Not white & & $4(9.09 \%)$ \\
\hline NI & & $6(13.64 \%)$ \\
\hline \multicolumn{3}{|l|}{ SAH n (\%) } \\
\hline Yes & & $26(59.1 \%)$ \\
\hline No & & 7 (15.9\%) \\
\hline NI & & $11(25 \%)$ \\
\hline \multicolumn{3}{|l|}{ Course DM (years) } \\
\hline Mean $\pm S D$ & & $13.66 \pm 6.58$ \\
\hline \multicolumn{3}{|l|}{ GBM thickness (nm) } \\
\hline Mean $\pm S D$ & & $750.69 \pm 184.03$ \\
\hline \multicolumn{3}{|l|}{ DN Classes (n) } \\
\hline Class 1 & & $2(4.5 \%)$ \\
\hline Class Ila & & $2(4.5 \%)$ \\
\hline Class IIb & & $2(4.5 \%)$ \\
\hline Class III & & $27(61.5 \%)$ \\
\hline Class IV & & $11(25 \%)$ \\
\hline \multicolumn{3}{|l|}{ Urea (mg/dL) } \\
\hline Mean $\pm S D$ & & $81.9 \pm 41.9$ \\
\hline \multicolumn{3}{|l|}{ Creatinine (mg/dL) } \\
\hline Mean $\pm S D$ & & $2.22 \pm 1.47$ \\
\hline \multicolumn{3}{|c|}{ eGFR $\left(\mathrm{mL} / \mathrm{min} / 1.73 \mathrm{~m}^{2}\right)$} \\
\hline Mean $\pm S D$ & & $48.46 \pm 34.51$ \\
\hline \multicolumn{3}{|l|}{ Proteinuria (g/day) } \\
\hline Mean $\pm S D$ & & $5.02 \pm 4.35$ \\
\hline
\end{tabular}

DN Diabetic Nephropathy. DM Diabetes Mellitus. SAH Systemic arterial hypertension. GBM Glomerular basement membrane. eGFR Estimated glomerular filtration rate. $S D$ Standard deviation.

a: $\mathrm{t}=0.8607 ; p=0.3927$

${ }^{\mathrm{b}}: \mathrm{x}^{2}=0.03417 ; p=0.8533$

differences between groups for MIP- $1 \alpha(p=0.3816 ; \mathrm{t}=$ 0.8811 , Fig. 3e and $\mathrm{f}$ ) expression.

We performed the analysis of cytokine and chemokine expressions in glomerular and tubulointerstitial compartments in DN and control group. The analysis of cytokine expressions in different compartments showed that DN group had a significant increase in IL-6 in glomerular $(p<0.0001, \mathrm{U}=77)$ and tubulointerstitial compartments $(p<0.0001, \mathrm{U}=48), \mathrm{IL}-1 \beta$ in glomerular $(p<0.0001, \mathrm{U}=179)$ and tubulointerstitial compartments $(p<0.0001, \mathrm{t}=5.325), \mathrm{IL}-4$ in glomerular $(p=$ $0.0014, \mathrm{U}=240)$ tubulointersticial compartments $(p<$ $0.0001, \mathrm{U}=137)$ and a decrease in TNFR1 in glomerular $(p=0.0124, \mathrm{t}=2.574)$ and tubulointerstitial compartments $(p=0.0503, \mathrm{U}=345.5)$ compared to the control group. However, there were no significant differences between groups for the cytokines IL-10 in glomerular $(p=0.3225, \mathrm{t}=0.9972)$ and tubulointerstitial compartments $(p=0.8036, \mathrm{U}=464.5)$ and TNF- $\alpha$ in glomerular $(p=0.2387, \mathrm{U}=396.5)$ and tubulointerstitial compartments $(p=0.2174, \mathrm{U}=392.5)$. Regarding the expression of chemokines in different compartments, we observed a significant increase in eotaxin in glomerular $(p=0.0359$, $\mathrm{U}=322)$ and tubulointerstitial compartments ( $p=$ $0.0007, \mathrm{U}=254)$ and decrease in glomerular IL-8 $(p=$ $0.0127, \mathrm{t}=2.563$ ) in the DN group compared to the control group. However, there was no significant difference between groups for tubulointerstitial IL-8 ( $p=0.1831$, $\mathrm{U}=395)$ and MIP- $1 \alpha$ in glomerular $(p=0.1487, \mathrm{t}=$ 1.462) and tubulointerstitial compartments $(p=0.9349$, $\mathrm{t}=0.08202)$.

\section{Relation of cytokines and chemokines in interstitial inflammation in diabetic nephropathy}

After determining the cytokine and chemokine expression profile in DN, we analyzed how these inflammatory mediators could be related to the interstitial inflammation of this disease. There was a significant increase in IL-6 in scores 0 and 1 compared to score $2(p=0.0035$; $\mathrm{F}=6.592$, Fig. 4a) and a significant increase in IL-10 in score 2 compared to score $0(p=0.0479 ; \mathrm{F}=3.295$, Fig. $4 b)$. For chemokines, there was a significant increase in eotaxin in score 2 compared to scores 0 and $1(p<$ $0.0001 ; \mathrm{H}=19.19$, Fig. 4c), whereas IL-8 ( $p=0.0513 ; \mathrm{F}=$ 3.208, Fig. 4d) and MIP- $1 \alpha(p=0.1801 ; \mathrm{F}=5.203$, Fig. $4 \mathrm{e})$ showed no significant differences between groups.

\section{Correlation between the estimated glomerular filtration rate (eGFR) and chemokine expression in diabetic nephropathy}

As there was a predominant increase in chemokine expression as interstitial inflammation progressed, the potential correlation between chemokine expression and decreased eGFR was analyzed in patients with DN. It was observed that only eotaxin tended to have a negative correlation with eGFR ( $p=0.0566 ; \mathrm{rS}=-0.3253$, Fig. 5).

\section{Correlation between proteinuria and cytokines/ chemokine expression in diabetic nephropathy}

A possible association between proteinuria and cytokine/ chemokine expression was tested in patients with DN. However, no significant correlation was found between IL-6 $(p=0.4123, \mathrm{rS}=-0.1453), \quad$ IL-1 $\beta \quad(p=0.5869, r=$ 


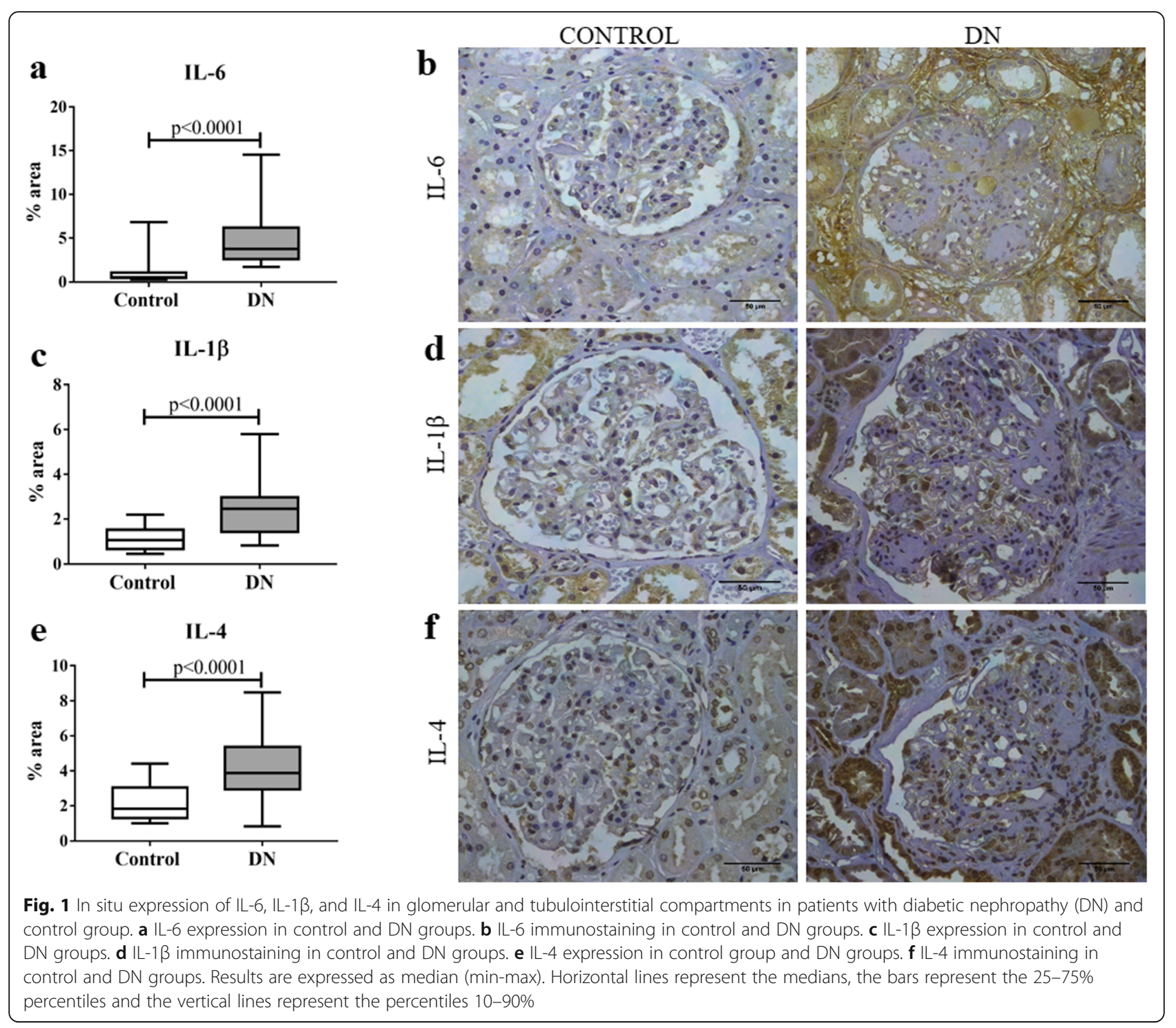

0.09509), IL-4 $(p=0.2707, r=0.1944)$, TNFR1 $\quad(p=$ $0.0637, r=0.3215)$, IL-10 $(p=0.4248, r=-0.1415)$, TNF$\alpha \quad(p=0.2167, r=-0.2174)$, Eotaxin $(p=0.1151, \mathrm{rS}=$ $0.2673)$, IL-8 $(p=0.6585, r=-0.0774), \operatorname{MIP}-1 \alpha \quad(p=$ $0.6225, r=-0.08755)$ and proteinuria.

\section{Discussion}

This study analyzed in situ expression of cytokines and chemokines in the renal biopsies of patients with $\mathrm{DN}$ and related this expression with interstitial inflammation and eGFR to improve our understanding of immune and inflammatory mechanisms that may act directly on kidney and decrease renal function.

Our results showed an increase expression of proinflammatory cytokines IL- 6 and IL-1 $\beta$, as well as of the Th2 cytokine, IL-4 and the chemokine eotaxin in patients with DN. In contrast, TNFR1 and IL-8 expression was reduced in DN. These findings suggest that in DN there may be a simultaneous sharing of cytokine actions of the innate and acquired immune response, associated with the increase of a potent eosinophilic chemokine. A study with microalbuminuric DMT2 patients demonstrated the activation of innate immunity in glomeruli of patients with DMT2 and early nephropathy and suggested that improved Toll-like receptors 4 (TLR4) signaling, expressed in native renal cells, may contribute to the progression of microalbuminuric for macroalbuminuric nephropathy [20]. In addition, it has already been proposed that the identification of transcriptional networks shared between human and mice glomeruli with DN may have a possible role in pathogenesis, which will allow a previous selection of the mouse model that most mimics human DN pathway under investigation [21]. 


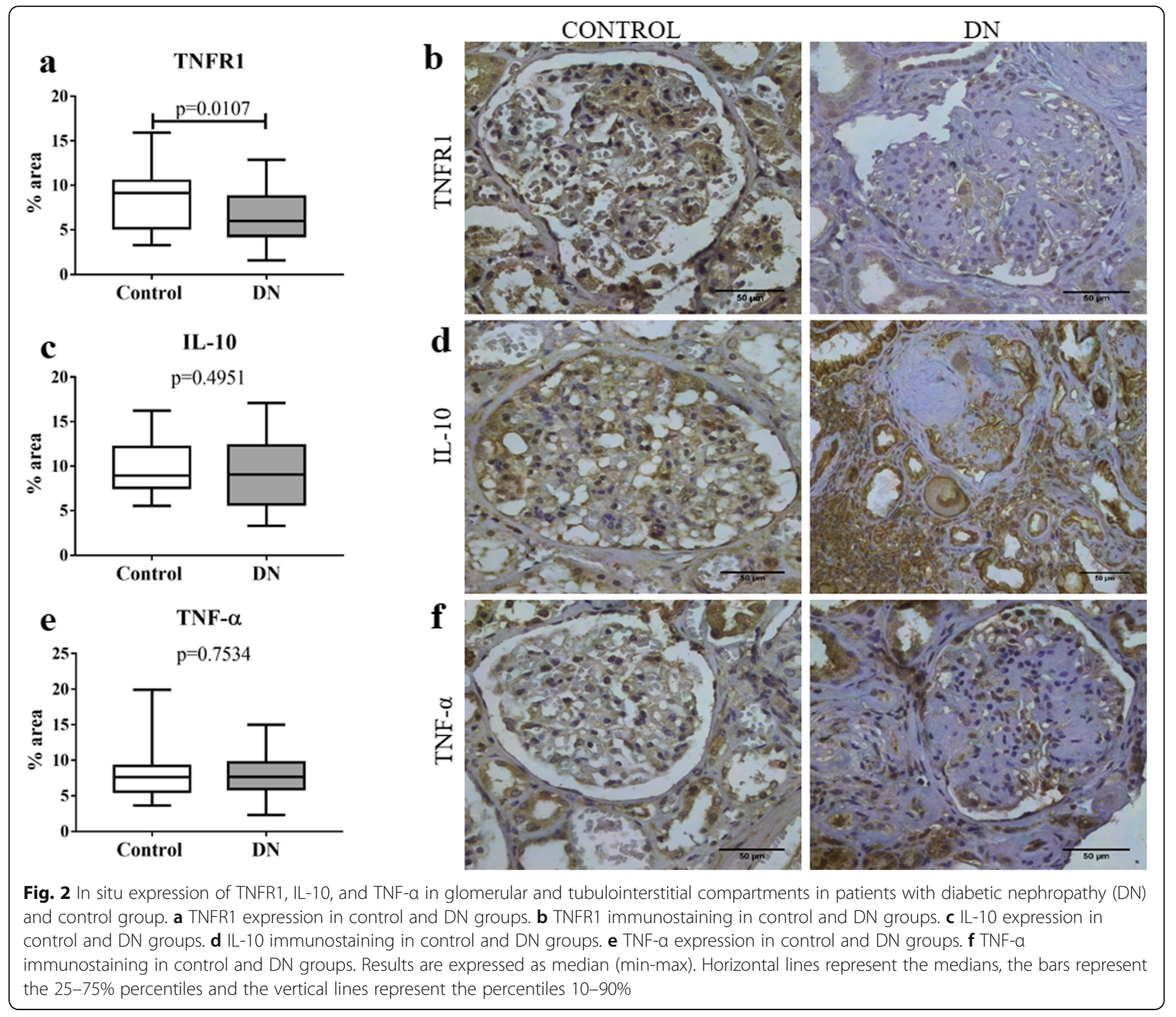

Eotaxin expression may play an important role in DN interstitial inflammation, as its expression was increased exclusively in score 2, in which interstitial inflammation is related to areas other than interstitial fibrosis and tubular atrophy (IFTA) and represents a more severe condition. On the other hand, IL- 6 expression was higher in scores 0 and 1 compared to score 2, whereas IL-10 expression was higher in score 2 compared to score 0 . Possibly, increase IL-10 expression in score 2 may be affecting IL- 6 expression through its pro-fibrotic and anti-inflammatory action.

In addition to the relationship between eotaxin increased expression and interstitial inflammation in patients with $\mathrm{DN}$, there is a correlation between eotaxin expression and decreased eGFR. Therefore, eotaxin on DN may influence both interstitial inflammation and eGFR, indicating its possible role in DN pathogenesis.
Kidney cells (endothelial, mesangial, epithelial, and tubular) are able to synthesize diferente cytokines and chemokines according to the cell and stimuli. Cytokines, chemokines, growth factors, adhesion molecules, nuclear factors, and immune cells, such as monocytes, lymphocytes, and macrophages, have been previously demonstrated to be implicated in DN pathogenesis [22-24]. In this study, patients with DN showed increased expression of IL-6, IL-1 $\beta$, IL-4 and eotaxin, and decreased expression of TNFR1 and IL- 8 both in glomerular and in tubulointerstitial compartment. Thus, it was observed that cells from both renal compartments may be involved in DN pathogenesis and, in this study, the expression of the analyzed cytokines and chemokines was similar in different renal compartments.

IL-1 $\beta$ and IL- 6 are among the cytokines that play an important role in DN pathogenesis, affecting renal resident and infiltrating cells. IL-1 $\beta$ induces the expression 


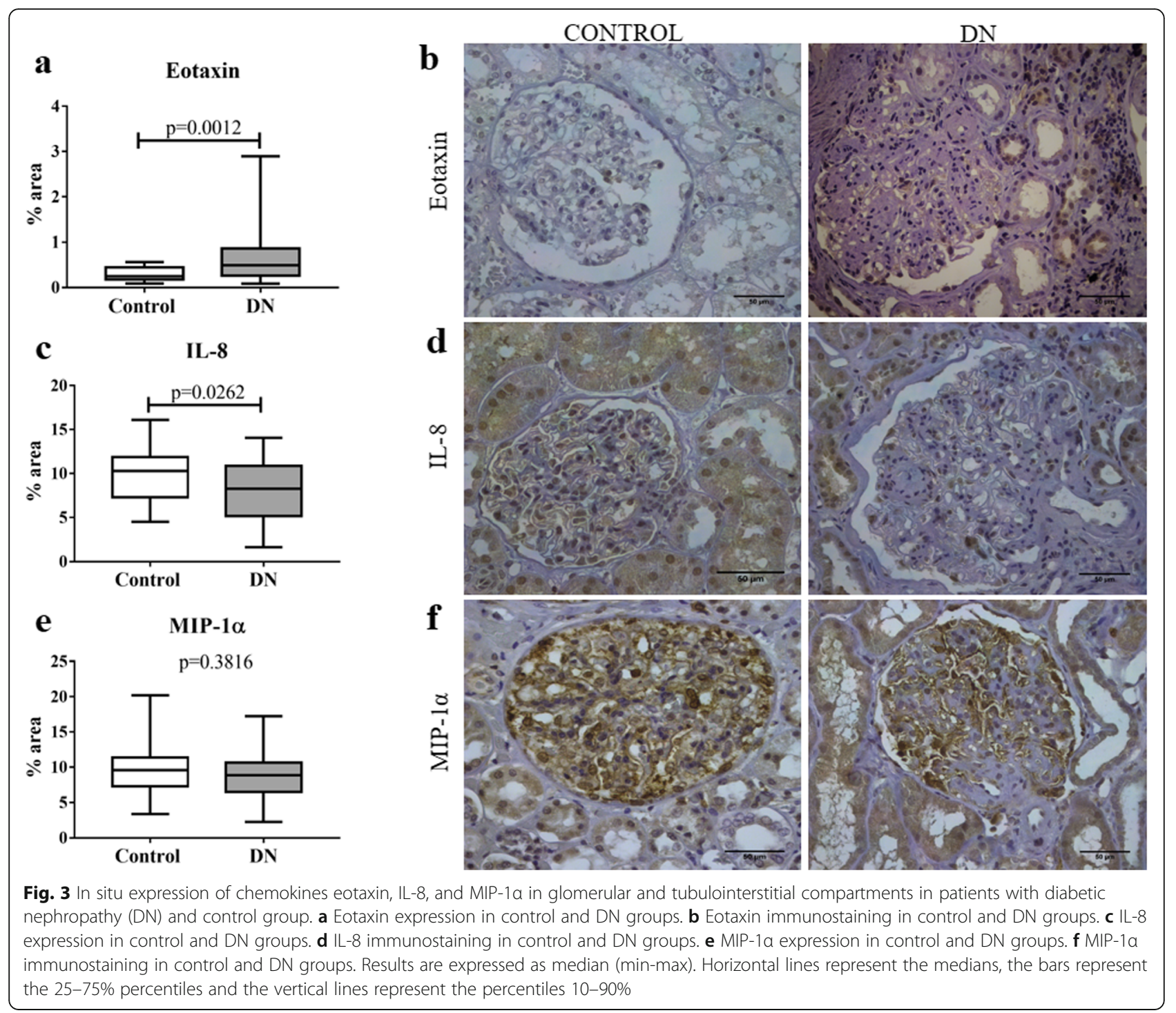

of the intercellular adhesion molecule 1 (ICAM-1) via mesangial and tubular cells and increases vascular permeability and chemokines expression, resulting in proliferation and synthesis of extracellular matrix (ECM) in glomerular mesangium [25]. IL-6 acts on mesangial cell proliferation and promotes ECM synthesis and GBM thickening, in addition to affecting vascular permeability and facilitating neutrophil infiltration into tubulointerstitium, leading to DN progression [24, 26]. Studies using experimental DN models have shown a correlation between increased renal expression of IL-1 $\beta$ and increased expression of chemotactic factors and adhesion molecules $[27,28]$. Previously, T2DM patients with DN were found to show an increased production of IL-6, which was associated with GBM thickness and was considered a strong marker of renal function decline [29]. As GBM thickening is the earliest morphological alteration in DN associated with increased IL- 6 production, it is possible that increased in situ IL-6 expression occurs from the early stages of DN, whereby patients show increased expression even without interstitial inflammation (score 0) or in score 1. Moreover, actions associated with increased IL-1 $\beta$ and IL- 6 expression promote greater cell infiltration in the kidney, which may exacerbate the inflammatory process and lead to impaired renal function.

Studies have reported that serum IL-10 levels are elevated in T2DM patients with $\mathrm{DN}$ and that there is a positive correlation between IL-10 and albuminuria [3032]. It has been shown that mononucleated cells are able to adopt an anti-inflammatory phenotype in tissue repair process later in the course of inflammation, which is believed to occur after exposure to IL-10. These cells eliminate cellular and matrix debris and generally promote the resolution of renal inflammation, stimulating renal tubular cell proliferation and angiogenesis [33]. Increased IL-10 production most probably represents a 


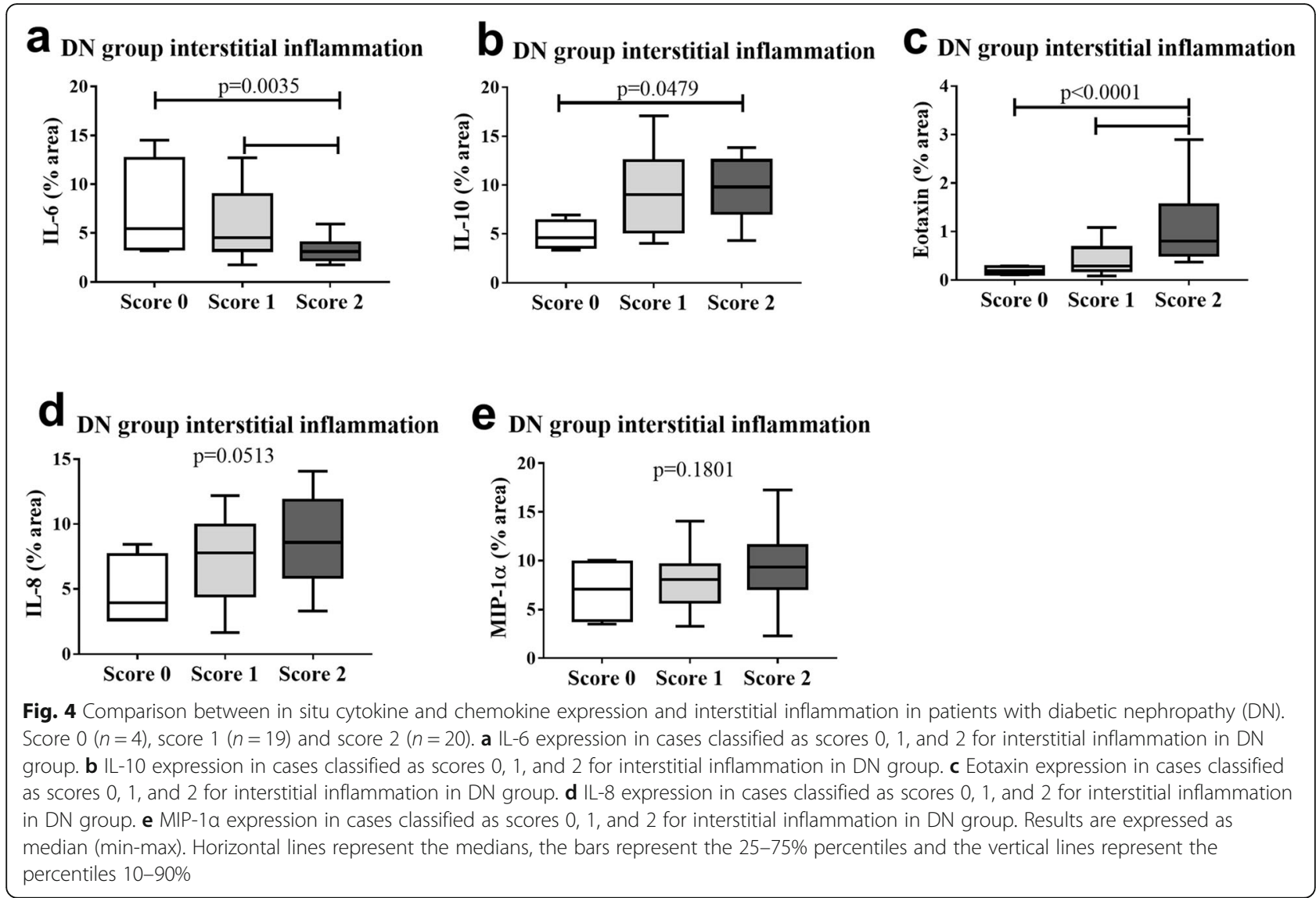

\section{DN group}

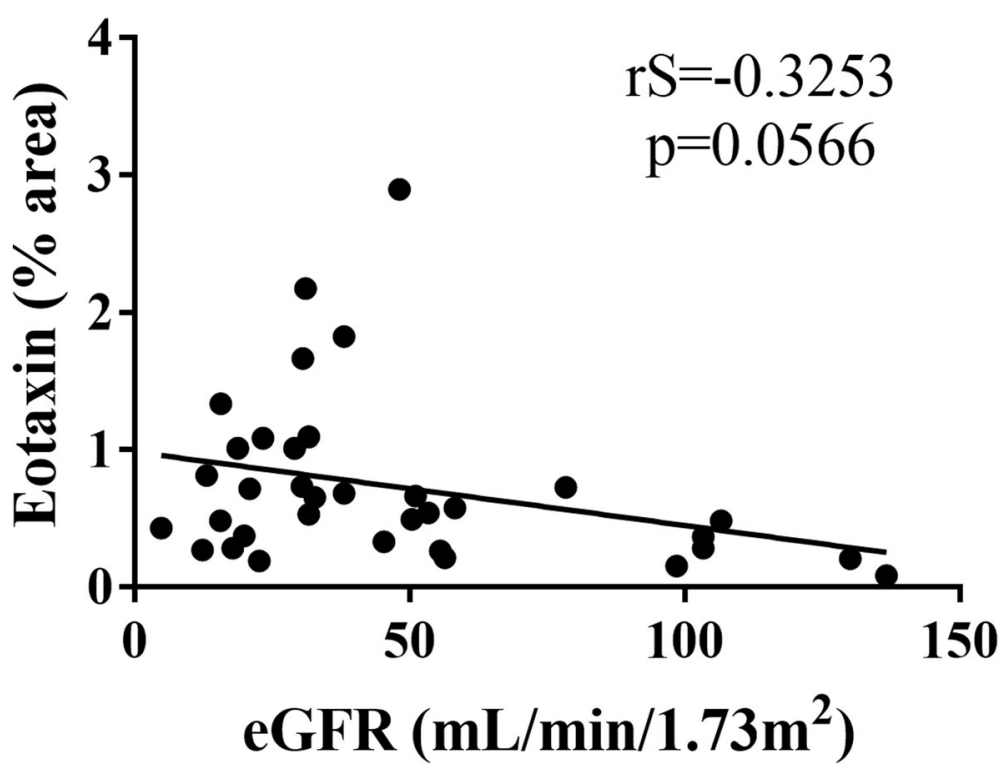

Fig. 5 Correlation between estimated glomerular filtration rate (eGFR) and in situ chemokine expression in patients with diabetic nephropathy (DN). Negative and significant correlation trend between eGFR and eotaxin in DN group 
compensatory mechanism due to proinflammatory cytokines increased expression and is a negative regulator of inflammation, which corroborates our findings.

Although IL-4 stimulates ECM synthesis through glomerular mesangial and epithelial cells, DN patients were found to have low serum levels of IL-4 [9]. Furthermore, no significant differences were found in this cytokine serum levels comparing patients with and without DN [14]. However, our results show that in situ expression of IL-4 is increased in patients with DN. The main morphological alteration associated with $\mathrm{DN}$ is progressive ECM accumulation, which may account for increased IL- 4 expression and suggests that the action of this cytokine in promoting ECM synthesis is more effective in situ than systemically.

Studies with T2DM patients have shown that only TNFR1 and TNFR2 receptors are associated with a risk of end-stage renal disease, wherein elevated serum levels of TNFR1 are associated with DN [34] and decreased renal function $[35,36]$. TNFR1 is mainly present in glomerular and endothelial cells of the peritubular capillaries [37]. High serum levels of TNFR1 have been associated with global sclerosis, increased ECM, decreased glomerular filtration, and foot process effacement in T2DM patients [38]. Although in vitro-activated TNFR1 induces tissue damage via proinflammatory signals and/or cell death [39], the mechanisms associating TNF receptors with DN remain unknown $[38,40]$. However, it has been shown that glomerular and tubular TNFR1 expression is not associated with a loss of renal function nor with any clinical parameters in DN patients [41]. Our results showed decreased in situ expression of TNFR1 in DN, which suggests that elevated serum levels of TNFR1 may be mostly implicated in DN progression.

Eotaxin is a CC chemokine that is specially chemotactic for eosinophils, from the activation of its CCR3 receptor, and is secreted by endothelial cells, macrophages, fibroblasts, and smooth muscle cells [42]. Roy et al. showed that eotaxin could be used as an independent predictor of renal failure. However, the relationship between an increased eotaxin plasma concentration and the progression to renal failure in diabetic patients remains poorly understood [43]. Elevated levels of urinary eotaxin are associated with prolonged hyperglycemia and microalbuminuria in T2DM patients [44]. In kidneys, eotaxin has been reported to contribute to renal interstitial eosinophilia; however, these results do not refer to DN [45].

The slow and continuous decline of renal function is associated with progressive tubulointerstitial damage and renal fibrosis, which is characterized by accumulation of leukocytes, fibroblasts, EMC and tubular atrophy $[2,46]$. Accumulation of macrophages and lymphocytes in interstitium is critical for tubular and interstitial damage, since these cells are the main sources of proinflammatory and pro-fibrotic cytokines $[47,48]$. Eotaxin is a potent chemoattractant chemokine and/or activator of eosinophils but may also be involved in the regulation of other cells. In atherosclerosis, smooth muscle cells express eotaxin and macrophages and mast cells express the CCR3 receptor, suggesting that eotaxin and its receptor contribute to recruitment and activation of inflammatory cells in ateroma [49]. It was also observed that Th2 lymphocytes, neutrophils, and bronchial endothelial cells also express the CCR3 receptor, suggesting the potential role of eotaxin in the non-eosinophilic inflammatory process [50,51].

Macrophages are the main inflammatory cells involved in renal damage, the accumulation of which is correlated with DN severity $[5,52,53]$ and mesangial expansion [54]. Mast cells also infiltrate tubulointerstitial compartment and release inflammatory mediators and proteolytic enzymes. The intensity of macrophage infiltration and the extent of mast cell degranulation has been previously associated with the level of tubulointerstitial inflammation and with decreased eGFR in DN [55]. Thus, we suggest that the increased in situ expression of eotaxin may be related to its contribution to recruitment and activation of cells other than eosinophils, which strongly promotes further infiltration and accumulation of these cells in kidneys. This may also account for the decreased in situ expression of IL-8 found in patients studied here. Eotaxin action associated with inflammatory cytokines role may worsen the inflammatory process and impair renal function, which corroborates our findings and suggests that eotaxin exerts an in situ role in DN pathogenesis.

In this study, most cases had advanced disease and we recognize this is a limitation of the study, clarified earlier. However, although $87 \%$ of our cases were in stage 3-4 of DN, this profile is expected in studies based on renal biopsies samples diagnosed with $\mathrm{DN}$ without overlapping with other non-diabetic renal disease [56], due to the indications of the procedure itself. Studies with DN patients showed that severity of glomerular and interstitial lesions had a significant impact on renal prognosis and could be used as independent risk factors for progression of $\mathrm{DN}[57,58]$.

Therefore, our findings indicate that in situ expression analysis of cytokines and chemokines, especially eotaxin, could be used to assist in analysis of renal function impairment based on the analysis of interstitial inflammation developed in patients with $\mathrm{DN}$.

\section{Conclusions}

Our results show that in situ expression of cytokines and chemokines, including IL- 6 , IL- $1 \beta$, IL- 4 and eotaxin, is increased in patients with DN. It was observed that, possibly, eotaxin may have an important role in progression of interstitial inflammation in DN and in the decrease of eGFR of these patients. 


\section{Abbreviations}

DN: Diabetic nephropathy; eGFR: Estimated glomerular filtration rate; ECM: Extracellular matrix; F: ANOVA test; FITC: Fluorescein isothiocyanate; GBM: Glomerular basement membrane; H: Kruskal-Wallis test; H\&E: Hematoxylin and eosin; ICAM-1: Intercellular adhesion molecule 1; IF: Direct immunofluorescence; IFTA: Interstitial fibrosis and tubular atrophy; Ig: Immunoglobulin; L: Interleukin; LM: Light microscopy; MIP-

1a: Macrophage inflammatory protein-1a; nm: Nanometers; r: Pearson test; rS: Spearman test; SAH: Systemic arterial hypertension; SD: Standard deviation; t: Student's t test; T2DM: Type 2 diabetes mellitus; TEM: Transmission electron microscopy; TNF-a: Tumor necrosis factor-a TNFR1: Tumor necrosis fator receptor-1; TNFR2: Tumor necrosis fator receptor-2; U: Mann Whitney test; X2: Chi square test

\section{Acknowledgements}

The authors appreciate the financial support of Conselho Nacional de Desenvolvimento Científico e Tecnológico (CNPq), Coordenação de Aperfeiçoamento de Pessoal de Nível Superior (CAPES), Fundação de Amparo à Pesquisa do Estado de Minas Gerais (FAPEMIG) and Fundação de Ensino e Pesquisa de Uberaba (FUNEPU).

The authors thank Federal University of Triângulo Mineiro, General Pathology Discipline and the following employees of the Nephropathology Service: Alberto Borba, Edson Santos, João Nolberto, Laura Penna, Lívia Alves and Vandair Gonçalves.

\section{Authors' contributions}

Conceptualization: JRM and LSA. Formal analysis: JRM and LSA. Performed the pathological diagnosis: MAR and MLGRM. Methodology: LSA, BGST, CAS, ALMSM and MVS. Supervised the manuscript: JRM. Wrinting - original draft: LSA. Wrinting - review and editing: LSA, BGST, CAS, ALMSM, MLGRM, MVS, MAR and JRM. All authors read and approved the final manuscript.

\section{Funding}

Not applicable.

\section{Availability of data and materials}

The datasets used and/or analysed during the current study are available from the corresponding author on reasonable request.

\section{Ethics approval and consent to participate}

Patients involved in the study signed a consent form and this study was approved by the Ethics Committee of the Federal University of Triângulo Mineiro, Protocol 3.001.006.

\section{Consent for publication}

Not applicable.

\section{Competing interests}

We declare not having conflict of interest related to this study.

\section{Author details}

'Discipline of General Pathology, Institute of Biological and Natural Sciences of Federal University of Triângulo Mineiro, Praça Manoel Terra, 330, Nossa Senhora da Abadia, Uberaba, Minas Gerais 38025-015, Brazil. 'Department of Microbiology, Immunology and Parasitology, Institute of Biological and Natural Sciences of Federal University of Triângulo Mineiro, Av. Getúlio Guaritá, n 130, Nossa Senhora da Abadia, Uberaba, Minas Gerais 38025-440, Brazil.

Received: 13 February 2020 Accepted: 17 July 2020

Published online: 28 July 2020

\section{References}

1. Cho NH, Shaw JE, Karuranga S, Huang Y, da Rocha Fernandes JD, Ohlrogge AW, et al. IDF diabetes atlas: global estimates of diabetes prevalence for 2017 and projections for 2045. Diabetes Res Clin Pract. 2018;138:271-81.

2. Lim CTS, Nordin NZ, Fadhlina NZ, Anim MS, Kalaiselvam T, Haikal WZ, et al. Rapid decline of renal function in patients with type 2 diabetes with heavy proteinuria: a report of three cases. BMC Nephrol. 2019;20(1):22.

3. Tuttle KR. Linking metabolism and immunology: diabetic nephropathy is an inflammatory disease. J Am Soc Nephrol. 2005;16(6):1537-8.
4. Mora C, Navarro JF. Inflammation and diabetic nephropathy. Curr Diab Rep. 2006;6(6):463-8

5. Wada J, Makino H. Inflammation and the pathogenesis of diabetic nephropathy. Clin Sci (Lond). 2013;124(3):139-52.

6. Araújo LS, MVd S, CAd S, MLR M, LHdM P, Rocha LP, et al. Cytokines and T helper cells in diabetic nephropathy pathogenesis. J Diabetes Mellitus. 2016; 6:230-46.

7. Navarro-González JF, Mora-Fernández C. The role of inflammatory cytokines in diabetic nephropathy. J Am Soc Nephrol. 2008;19(3):433-42.

8. Niemir Zl, Stein H, Ciechanowicz A, Olejniczak P, Dworacki G, Ritz E, et al. The in situ expression of interleukin-8 in the normal human kidney and in different morphological forms of glomerulonephritis. Am J Kidney Dis. 2004; 43(6):983-98.

9. Perlman AS, Chevalier JM, Wilkinson P, Liu H, Parker T, Levine DM, et al. Serum inflammatory and immune mediators are elevated in early stage diabetic nephropathy. Ann Clin Lab Sci. 2015;45(3):256-63.

10. Nowak N, Skupien J, Smiles AM, Yamanouchi M, Niewczas MA, Galecki AT, et al. Markers of early progressive renal decline in type 2 diabetes suggest different implications for etiological studies and prognostic tests development. Kidney Int. 2018;93(5):1198-206.

11. Liu J, Zhao Z, Willcox MD, Xu B, Shi B. Multiplex bead analysis of urinary cytokines of type 2 diabetic patients with normo- and microalbuminuria. J Immunoassay Immunochem. 2010;31(4):279-89.

12. Liu G, Deng Y, Sun L, Ye X, Yao P, Hu Y, et al. Elevated plasma tumor necrosis factor-a receptor 2 and resistin are associated with increased incidence of kidney function decline in Chinese adults. Endocrine. 2016; 52(3):541-9.

13. Zhang $D, Y e S$, Pan $T$. The role of serum and urinary biomarkers in the diagnosis of early diabetic nephropathy in patients with type 2 diabetes. PeerJ. 2019;7:e7079.

14. Wu CC, Chen JS, Lu KC, Chen CC, Lin SH, Chu P, et al. Aberrant cytokines/ chemokines production correlate with proteinuria in patients with overt diabetic nephropathy. Clin Chim Acta. 2010;411(9-10):700-4.

15. Wu CC, Sytwu HK, Lu KC, Lin YF. Role of T cells in type 2 diabetic nephropathy. Exp Diabetes Res. 2011;2011:514738.

16. Nelson RG, Tuttle KR. The new KDOQI clinical practice quidelines and clinical practice recommendations for diabetes and CKD. Blood Purif. 2007; 25(1):112-4.

17. Ritz E. Clinical manifestations and natural history of diabetic kidney disease. Med Clin North Am. 2013:97(1):19-29

18. da Silva CA, Araújo LS, Dos Reis Monteiro MLG, de Morais Pereira LH, da Silva MV, Castellano LRC, et al. Evaluation of the diagnostic potential of UPAR as a biomarker in renal biopsies of patients with FSGS. Dis Markers. 2019;2019:1070495.

19. Tervaert TW, Mooyaart AL, Amann K, Cohen AH, Cook HT, Drachenberg CB, et al. Pathologic classification of diabetic nephropathy. J Am Soc Nephrol. 2010;21(4):556-63.

20. Verzola D, Cappuccino L, D'Amato E, Villaggio B, Gianiorio F, Mij M, et al. Enhanced glomerular toll-like receptor 4 expression and signaling in patients with type 2 diabetic nephropathy and microalbuminuria. Kidney Int. 2014;86(6):1229-43.

21. Hodgin JB, Nair V, Zhang H, Randolph A, Harris RC, Nelson RG, et al. Identification of cross-species shared transcriptional networks of diabetic nephropathy in human and mouse glomeruli. Diabetes. 2013;62(1):299308.

22. Navarro-González JF, Mora-Fernández C. Muros de Fuentes M, García-Pérez J. inflammatory molecules and pathways in the pathogenesis of diabetic nephropathy. Nat Rev Nephrol. 2011;7(6):327-40.

23. García-García PM, Getino-Melián MA, Domínguez-Pimentel V, NavarroGonzález JF. Inflammation in diabetic kidney disease. World J Diabetes. 2014;5(4):431-43.

24. Pérez-Morales RE, Del Pino MD, Valdivielso JM, Ortiz A, Mora-Fernández C, Navarro-González JF. Inflammation in diabetic kidney disease. Nephron. 2019;143(1):12-6.

25. Donate-Correa J, Martín-Núñez E, Muros-de-Fuentes M, Mora-Fernández C Navarro-González JF. Inflammatory cytokines in diabetic nephropathy. J Diabetes Res. 2015;2015:948417.

26. Duran-Salgado MB, Rubio-Guerra AF. Diabetic nephropathy and inflammation. World J Diabetes. 2014;5(3):393-8.

27. Navarro JF, Milena FJ, Mora C, León C, García J. Renal pro-inflammatony cytokine gene expression in diabetic nephropathy: effect of angiotensin- 
converting enzyme inhibition and pentoxifylline administration. Am J Nephrol. 2006;26(6):562-70.

28. Sassy-Prigent C, Heudes D, Mandet C, Bélair MF, Michel O, Perdereau B, et al. Early glomerular macrophage recruitment in streptozotocin-induced diabetic rats. Diabetes. 2000;49(3):466-75.

29. Dalla Vestra M, Mussap M, Gallina P, Bruseghin M, Cernigoi AM, Saller A et al. Acute-phase markers of inflammation and glomerular structure in patients with type 2 diabetes. J Am Soc Nephrol. 2005;16(Suppl 1):S78-82.

30. Myśliwska J, Zorena K, Semetkowska-Jurkiewicz E, Rachoń D, Suchanek H, Myśliwski A. High levels of circulating interleukin-10 in diabetic nephropathy patients. Eur Cytokine Netw. 2005;16(2):117-22.

31. Wong CK, Ho AW, Tong PC, Yeung CY, Kong AP, Lun SW, et al. Aberrant activation profile of cytokines and mitogen-activated protein kinases in type 2 diabetic patients with nephropathy. Clin Exp Immunol. 2007;149(1):12331.

32. Fathy SA, Mohamed MR, Ali MAM, El-Helaly AE, Alattar AT. Influence of IL-6, IL-10, IFN- $\gamma$ and TNF-a genetic variants on susceptibility to diabetic kidney disease in type 2 diabetes mellitus patients. Biomarkers. 2019;24(1):43-55.

33. Nelson PJ, Rees AJ, Griffin MD, Hughes J, Kurts C, Duffield J. The renal mononuclear phagocytic system. J Am Soc Nephrol. 2012;23(2):194-203.

34. Niewczas MA, Gohda T, Skupien J, Smiles AM, Walker WH, Rosetti F, et al. Circulating TNF receptors 1 and 2 predict ESRD in type 2 diabetes. J Am Soc Nephrol. 2012;23(3):507-15.

35. Doody A, Jackson S, Elliott JA, Canavan RJ, Godson C, Slattery D, et al. Validating the association between plasma tumour necrosis factor receptor 1 levels and the presence of renal injury and functional decline in patients with type 2 diabetes. J Diabetes Complicat. 2018;32(1):95-9.

36. Mokhtar ER. M E, Hassan MA, Abou-ELHassan HA, Alanany MG, Hasuna MA. Association of sTNFR1 and BNP levels with diminished estimated glomerular filtration rate in type 2 diabetic Egyptian patients. Egypt J Immunol. 2018; 25(1):57-69

37. Al-Lamki RS, Wang J, Skepper JN, Thiru S, Pober JS, Bradley JR. Expression of tumor necrosis factor receptors in normal kidney and rejecting renal transplants. Lab Investig. 2001;81(11):1503-15.

38. Pavkov ME, Weil EJ, Fufaa GD, Nelson RG, Lemley KV, Knowler WC, et al. Tumor necrosis factor receptors 1 and 2 are associated with early glomerular lesions in type 2 diabetes. Kidney Int. 2016;89(1):226-34.

39. Fernández-Real JM, Vendrell J, García I, Ricart W, Vallès M. Structural damage in diabetic nephropathy is associated with TNF-a system activity. Acta Diabetol. 2012;49(4):301-5.

40. Hojs R, Ekart R, Bevc S, Hojs N. Markers of inflammation and oxidative stress in the development and progression of renal disease in diabetic patients. Nephron. 2016;133(3):159-62.

41. Hwang S, Park J, Kim J, Jang HR, Kwon GY, Huh W, et al. Tissue expression of tubular injury markers is associated with renal function decline in diabetic nephropathy. J Diabetes Complicat. 2017;31(12):1704-9.

42. Garcia-Zepeda EA, Rothenberg ME, Ownbey RT, Celestin J, Leder P, Luster AD. Human eotaxin is a specific chemoattractant for eosinophil cells and provides a new mechanism to explain tissue eosinophilia. Nat Med. 1996; 2(4):449-56

43. Roy MS, Janal MN, Crosby J, Donnelly R. Markers of endothelial dysfunction and inflammation predict progression of diabetic nephropathy in African Americans with type 1 diabetes. Kidney Int. 2015;87(2):427-33.

44. Cherney DZ, Scholey JW, Sochett E, Bradley TJ, Reich HN. The acute effect of clamped hyperglycemia on the urinary excretion of inflammatory cytokines/chemokines in uncomplicated type 1 diabetes: a pilot study. Diabetes Care. 2011;34(1):177-80.

45. Wada T, Furuichi K, Sakai N, Shimizu M, Segawa C, Kobayashi K, et al. Eotaxin contributes to renal interstitial eosinophilia. Nephrol Dial Transplant. 1999;14(1):76-80

46. Becker GJ, Hewitson TD. The role of tubulointerstitial injury in chronic renal failure. Curr Opin Nephrol Hypertens. 2000;9(2):133-8.

47. Eddy AA. Molecular basis of renal fibrosis. Pediatr Nephrol. 2000;15(3-4): 290-301.

48. Eddy AA. Progression in chronic kidney disease. Adv Chronic Kidney Dis. 2005;12(4):353-65.

49. Haley KJ, Lilly CM, Yang JH, Feng Y, Kennedy SP, Turi TG, et al. Overexpression of eotaxin and the CCR3 receptor in human atherosclerosis: using genomic technology to identify a potential novel pathway of vascular inflammation. Circulation. 2000;102(18):2185-9.
50. Sallusto F, Mackay CR, Lanzavecchia A. Selective expression of the eotaxin receptor CCR3 by human T helper 2 cells. Science. 1997;277(5334):2005-7.

51. Ying S, Robinson DS, Meng Q, Barata LT, McEuen AR, Buckley MG, et al. C-C chemokines in allergen-induced late-phase cutaneous responses in atopic subjects: association of eotaxin with early 6-hour eosinophils, and of eotaxin-2 and monocyte chemoattractant protein-4 with the later 24-hour tissue eosinophilia, and relationship to basophils and other C-C chemokines (monocyte chemoattractant protein-3 and RANTES). J Immunol. 1999;163(7): 3976-84.

52. Pichler R, Afkarian M, Dieter BP, Tuttle KR. Immunity and inflammation in diabetic kidney disease: translating mechanisms to biomarkers and treatment targets. Am J Physiol Renal Physiol. 2017;312(4):F716-F31.

53. Anders HJ. Innate versus adaptive immunity in kidney immunopathology. BMC Nephrol. 2013;14:138.

54. Hartner A, Veelken R, Wittmann M, Cordasic N, Hilgers KF. Effects of diabetes and hypertension on macrophage infiltration and matrix expansion in the rat kidney. BMC Nephrol. 2005;6:6.

55. Alicic RZ, Johnson EJ, Tuttle KR. Inflammatory mechanisms as new biomarkers and therapeutic targets for diabetic kidney disease. Adv Chronic Kidney Dis. 2018;25(2):181-91.

56. Zhu X, Liu F, Peng Y, Liu H, Yuan S, Xu X, et al. New pathologic classification of diabetic nephropathy (retrospective study of 37 cases). Zhong Nan Da Xue Xue Bao Yi Xue Ban. 2012;37(2):185-9.

57. An Y, Xu F, Le $W, G e Y, Z$ hou $M$, Chen $H$, et al. Renal histologic changes and the outcome in patients with diabetic nephropathy. Nephrol Dial Transplant. 2015:30(2):257-66.

58. Qi C, Mao X, Zhang Z, Wu H. Classification and differential diagnosis of diabetic nephropathy. J Diabetes Res. 2017;2017:8637138.

\section{Publisher's Note}

Springer Nature remains neutral with regard to jurisdictional claims in published maps and institutional affiliations.

Ready to submit your research? Choose BMC and benefit from:

- fast, convenient online submission

- thorough peer review by experienced researchers in your field

- rapid publication on acceptance

- support for research data, including large and complex data types

- gold Open Access which fosters wider collaboration and increased citations

- maximum visibility for your research: over $100 \mathrm{M}$ website views per year

At $\mathrm{BMC}$, research is always in progress.

Learn more biomedcentral.com/submissions 